\title{
Ecologia de saberes na prática: O trabalho da tradução no Fórum Social Mundial e na Universidade Popular dos Movimentos Sociais
}

Ecología de saberes en la práctica: El trabajo de traducción en el Foro Social Mundial y en la Universidad Popular de los Movimientos Sociales

Ecology of knowledge on the ground: The work of translation at the World Social Forum and the Popular University of Social Movements

Fábio André Diniz MERLADET ${ }^{1}$ Isabella Gonçalves MIRANDA²

\section{RESUMO}

O objetivo deste trabalho é comparar as estratégias de tradução adotadas para promover a ecologia de saberes no Fórum Social Mundial e na Universidade Popular dos Movimentos Sociais. Para tanto, procede-se a uma abordagem teórica dos conceitos de tradução e ecologia de saberes e, em seguida, apresenta-se o contexto de surgimento do Fórum Social Mundial, bem como as experiências de emergência, agregação e articulação dos movimentos sociais por ele possibilitadas. Analisa-se também os avanços e contribuições da Universidade Popular dos Movimentos Sociais para a construção de uma metodologia da tradução. Encerra-se o artigo com as divergências e convergências entre as duas experiências e com os campos em que poderiam colaborar e aprender reciprocamente.

Palavras chave: fórum social mundial; universidade popular dos movimentos sociais; tradução; ecologia de saberes; diversidade; encontro.

\section{RESUMEN}

El objetivo de este estudio es comparar las estrategias de traducción adoptadas para promover la ecología de saberes, en el Foro Social Mundial y en la Universidad Popular de los Movimientos Sociales. Con este fin, se presenta una aproximación teórica a los conceptos de la traducción y la ecología de saberes y luego se presenta el contexto del surgimiento del Foro Social Mundial,

1 Bacharel em Ciências Sociais pela Universidade Federal de Minas Gerais (UFMG), pesquisador do Programa Pólos de Cidadania da Faculdade de Direito da UFMG; pesquisador do Projeto ALICE. Contato: fabioandredm@, hotmail.com. Endereço: Programa Pólos de Cidadania, Faculdade de Direito da Universidade Federal de Minas Gerais. Avenida João Pinheiro, 100 Centro 30130180 - Belo Horizonte, MG - Brasil

2 Doutoranda em Pós Colonialismos e Cidadania Global pelo Centro de Estudos Sociais da Universidade de Coimbra (Portugal); Bacharel em Ciências Sociais pela Universidade Federal de Minas Gerais (UFMG). E-mail: bellagm2@ hotmail.com 
así como las experiencias de emergencia, agregación y articulación de los movimientos sociales por él permitido. También se analizaron los avances y aportes de la Universidad Popular de los Movimientos Sociales para la construcción de una metodología de la traducción, finalizando con las diferencias y similitudes entre las dos experiencias y los campos en los que podrían colaborar y aprender mutuamente.

Palabras clave: foro social mundial; universidad popular de los movimientos sociales; traducción; ecología de saberes; diversidad; encuentro.

\begin{abstract}
This essay aims to compare strategies of translation adopted to promote the ecology of knowledge at the World Social Forum and the Popular University of Social Movements. Therefore, we present a theoretical approach to the concepts of translation and ecology of knowledge. Then we present the context of the emergence of the World Social Forum, as well as the experiences of emergence, aggregation and articulation of social movements made possible by the WSF. We also analyze enhancements and contributions made by the Popular University of Social Movements for the construction of a methodology of translation. Finally we discuss divergences and convergences between both experiences, as well as we propose fields in which they could collaborate and promote mutual learning experiences.
\end{abstract}

Key Words: World Social Forum; Popular University of Social Movements; translation; ecology of knowledge; diversity, encounter.

\title{
INTRODUÇÃO
}

O presente artigo parte do que penso ser um conjunto de perguntas fortes que são fonte de grande perplexidade para muitos de nós: como deixar de ver a diversidade como um fator de fragmentação ou isolacionismo e passar a enxergá-la como uma possibilidade histórica de construir novos caminhos compartilhados? Como trazer a tona as mais diversas e impronunciáveis aspirações dos oprimidos para que elas possam dialogar na busca e na luta por outro mundo possível? Como converter a diferença em um espaço de encontro, de partilha e de solidariedade entre todos? Ou ainda, em outras palavras, quais os saberes que nos faltam para captar e articular a inesgotável diversidade do mundo?

Sabendo não ser possível dar uma resposta suficientemente satisfatória a essas perguntas que nos afligem, este trabalho limita-se a contextualizar os conceitos de tradução e ecologia de saberes para, em seguida, realizar uma analise comparativa entre duas das mais significativas experiências de ecologia de saberes do momento presente: O Fórum Social Mundial (FSM) e a Universidade Popular dos Movimentos Sociais (UPMS). Este artigo tem, portanto, o objetivo de comparar as práticas e estratégias de tradução levadas a cabo pelo FSM e pela UPMS para promover a ecologia 
de saberes.

A palavra tradução transmite a ideia de "levar de um lado para o outro" e é um termo que as ciências sociais tomam emprestado dos estudos da linguagem para pensar as possibilidades de intercâmbio de saberes e experiências entre diferentes culturas. $\mathrm{O}$ conceito de tradução tem uma longa tradição reflexiva que vem desde a antiguidade grega, mas é a partir da primeira metade do século XX que ele passa a ser desenvolvido na antropologia e nas ciências sociais, assumindo um lugar central nos estudos culturais e sociais ${ }^{1,2}$. Desde então, são muitos os que empregaram o conceito nos mais diversos campos das humanidades, alargando o seu significado. No entanto, não vou pelo caminho de realizar uma longa contextualização histórica do conceito, pois, para fins desse artigo, o que nos interessa é compreender como ele tem sido incorporado e utilizado como ferramenta emancipatória no FSM e na UPMS.

De acordo com Antonio Sousa Ribeiro, "o conceito de tradução aponta para a forma como não apenas línguas diferentes, mas também culturas diferentes e diferentes contextos e práticas políticos e sociais podem ser postos em contato de forma a que se tornem mutuamente inteligíveis, sem que com isso tenha que se sacrificar a diferença em nome de um princípio de assimilação"3. Essa definição de tradução é bastante próxima da formulação feita por Boaventura de Sousa Santos, para quem a tradução "é o procedimento que permite criar inteligibilidade recíproca entre as experiências do mundo, [...] sem pôr em perigo a sua identidade e autonomia, sem, por outras palavras, as reduzir a entidades homogêneas"4.

No entanto, só é possível pensarmos uma tradução nos termos de Ribeiro e de Santos se estivermos dispostos a reconhecer que há uma diversidade infinita de formas de conhecer, de experimentar e de se relacionar com o mundo, ou seja, se estivermos dispostos a reconhecer a ecologia de práticas e de saberes que compõem o mundo. A ecologia de saberes é uma articulação entre múltiplos conhecimentos que "tem como premissa a ideia da diversidade epistemológica do mundo, o reconhecimento da existência de uma pluralidade potencialmente infinita de formas de conhecimento além do conhecimento cientifico"s. É a partir dessa outra concepção epistemológica que podemos pensar a tradução nos termos do FSM e da UPMS como um trabalho que pretende reinventar a nossa experiência confrontando-a com a imensa variedade de experiências contrahegemônicas que desconhecíamos ou cuja existência ignorávamos. Utilizamos como metodologia para as análises e reflexões deste artigo a nossa própria experiência enquanto participantes e ativistas tanto do FSM quanto da UPMS. Dada a relevância das duas experiências, bem como as suas profundas e insuspeitadas conexões, realizamos a seguir uma análise comparativa entre elas contextualizando o surgimento de cada uma e comparando as semelhanças e diferenças das estratégias de tradução adotadas para promover a ecologia de saberes.

\section{O fórum social mundial e a emergência da diversidade}

O século XX demonstrou, com uma crueldade enorme, a derrota, dissolução e morte de 
praticamente todas as utopias de uma sociedade não capitalista. Com a queda do Muro de Berlim e a desintegração da URSS foi-se o sonho do socialismo, a ponto de teóricos como Fukuyama decretarem o "Fim da História" . O socialismo real da União Soviética e do Leste Europeu havia se revelado um fracasso e, portanto, estávamos todos condenados a aceitar as injustiças do capitalismo e as sociedades desiguais. Livre da disputa ideológica com o bloco socialista, o capitalismo teve ampla hegemonia para se impor como o único presente e futuro possível.

É nesse contexto e contra ele que, em janeiro de 2001, no mesmo momento em que ocorria o Fórum Econômico Mundial de Davos, manifestantes, intelectuais, estudantes e ativistas de todo o mundo reuniram-se em Porto Alegre dando início à mais abrangente manifestação política contrahegemônica da história contemporânea: o Fórum Social Mundial que, contrapondo-se à famosa frase de Margaret Thatcher, "Não há alternativa", adotou o lema "Um outro mundo é possível”, com o objetivo de desconstruir as teses do pensamento único. Não por acaso, durante a primeira edição do FSM o Le Monde Diplomatique publicou na capa de seus jornais: “O século XXI nasce em Porto Alegre"'.

Há uma expressiva quantidade de autores que relatam a criação, surgimento e desenvolvimento do FSM, entre eles Santos ${ }^{4,8}$, Whitaker ${ }^{9}$, Gadotti $^{10}$ e Leite ${ }^{11}$. Para fins deste artigo interessa-nos apenas observar que, em um contexto no qual as políticas neoliberais estavam a ser impostas em boa parte do mundo como o único caminho possível, o Fórum Social Mundial foi capaz de colocar em destaque os movimentos, experiências e alternativas do Sul do mundo dando força, visibilidade e legitimidade a vozes antes impronunciáveis, vozes cujas reivindicações e critérios de emancipação se projetam para muito além dos horizontes da globalização neoliberal. Por vez primeira na história havia um espaço onde a ampla diversidade contra-hegemônica podia se encontrar sem o risco de ser reduzida ou incorporada a outras experiências dominantes e isso fez com que o Fórum fosse capaz de abrigar uma enorme multiplicidade de movimentos, iniciativas, organizações, práticas e alternativas que, das mais inusitadas maneiras, resistem à globalização neoliberal.

De fato, a novidade do FSM foi responsável por uma grande euforia, mas o entusiasmo veio acompanhado de um enorme espanto e perplexidade. A euforia advém do fato de testemunhar as teses do fim da história e do pensamento único sendo confrontadas por uma ampla e inimaginável diversidade de alternativas que emergiam de todos os cantos. O espaço do Fórum provocou uma ampliação do mundo, não só porque nele surgem novas experiências sociais, mas também porque a multiplicação de alternativas aumenta as possibilidades de experimentação social no futuro.

Já o espanto e a perplexidade advêm da constatação da impossibilidade de construir uma teoria geral capaz de abarcar coerentemente toda essa imensa diversidade emergente. O Fórum demonstrou que as teorias produzidas pelas ciências sociais eram totalmente impotentes para dar conta da diversidade do mundo e que, longe de captar essa diversidade, a ciência foi, na maioria das vezes, a responsável por sua invisibilidade. Daí que Santos afirme que "nenhuma teoria unificada poderá alguma vez traduzir, de uma maneira coerente, o imenso mosaico de movimentos, lutas e 
iniciativas", e que "qualquer que seja o seu valor, a teoria virá sempre por último, não em primeiro lugar" 12 .

O discurso académico e científico, junto com seus métodos, suas variáveis, seu rigor, sua erudição, sua arrogância e sua pretensão de neutralidade, tem se apresentado como o único legítimo produtor de conhecimentos válidos, desprezando e invisibilizando todas as demais experiências que têm lugar no mundo, experiências estas que o Fórum soube acolher e dar visibilidade.

É contra este "desperdício da experiência" provocado pela "razão indolente"12-15, e a partir deste espanto e perplexidade causado pela diversidade emergente no FSM que surge então a pergunta forte: Quais os saberes que nos faltam para captar e articular a inesgotável diversidade do mundo?

Aqui chegamos aos limites do Fórum. Se o FSM foi fecundo em dar voz e visibilidade às infinitas experiências de resistência à globalização hegemônica, ele próprio viu-se diante da dificuldade de tornar traduzíveis essas mesmas experiências que nele emergiram e não teve a mesma vitalidade para fazer com que essa extraordinária diversidade revelada fosse capaz de construir uma inteligibilidade recíproca, não só entre saberes, mas também entre práticas, formas de organização e objetivos de ação.

Como criar inteligibilidade recíproca entre tão diferentes escalas, objetivos, temporalidades, formas de organização e princípios políticos? "Trata-se de um trabalho muito complexo, não só pelo numero e diversidade de movimentos e organizações envolvidos, como, sobretudo, pelo fato de uns e outras estarem ancorados em culturas e saberes muito diversos"14.

O desafio é imenso porque, além de serem muitos e muito diversificados, cada um dos movimentos possui sua própria linguagem e vocabulário, seus próprios discursos e suas próprias formas de ação e de intervenção no mundo que consideram as melhores, quando não as únicas possíveis.

Como se não bastasse, há também muitos preconceitos, conflitos e duras críticas entre os movimentos, sendo que muitos deles consideram-se em campos políticos opostos e possuem ressentimentos, disputas e rivalidades entre si. Há, por exemplo, movimentos que ouvem com desconfiança a palavra "revolução" e outros que ouvem com desconfiança a palavra "reforma", há quem conteste o uso da palavra "gênero" e quem a reivindique como um conceito emancipatório, há quem pense que as ações diretas provocam sempre violência e há quem associe sempre as ações institucionais com cooptação ou "peleguismo". Muitas das integrantes de movimentos feministas, por exemplo, consideram os sindicatos machistas, e muitos dos sindicalistas consideram as feministas lésbicas (o que é um duplo preconceito tanto com as feministas quanto com os movimentos LGBT que lutam pela igualdade de direitos e pela liberdade sexual), muitos dos camponeses que lutam pelo direito à terra consideram os indígenas "bêbados e preguiçosos que querem viver às custas do Estado", e muitos dos indígenas que igualmente lutam pelo direito à terra consideram os camponeses "preguiçosos invasores de terras que querem viver às custas do Estado". Ora, nessas condições de 
fragmentação, isolamento e preconceitos mútuos é muito difícil construir espaços de encontro e de tradução que resultem em uma ecologia de saberes potencializadora das lutas sociais levadas a cabo pelos diferentes movimentos.

Mesmo assim, o FSM, ao longo de suas sucessivas edições, elaborou e experimentou uma série de estratégias com o intuito tanto de ampliar ainda mais a diversidade infinita do mundo, quanto de tornar possível a articulação dos movimentos que compõem essa diversidade.

A história do Fórum Social Mundial é testemunha do esforço empreendido para criar espaços que promovessem, simultaneamente, a emergência da diversidade contra-hegemônica e a tradução dessa diversidade. A título de exemplo, apresento a seguir algumas das experimentações levadas a cabo pelo Fórum no esforço de simultaneamente captar e articular a diversidade contra-hegemônica do mundo.

\section{O fórum social mundial e as tentativas de articulação da diversidade}

Tendo inicialmente começado como um evento que convidava seus palestrantes, ou seja, que definia as formas de saber por ele consideradas legítimas, o Fórum rapidamente aprendeu a criar espaços sem definir quem neles participa, concebendo as atividades autogestionadas. Nas edições seguintes, bastava se inscrever antes do evento para que os movimentos e organizações tivessem um espaço próprio para montar seus painéis, levar adiante seus debates e divulgar suas causas. Sendo, a princípio, um evento com formato bastante acadêmico de grandes conferências com renomados palestrantes, também rapidamente o Fórum procurou tornar viável a presença simultânea de palestras, mesas redondas, debates, oficinas, círculos de conversa, assembleias, dança, música, pintura, grafite, cinema, exposições fotográficas, documentários, artes plásticas, peças de teatro, acampamentos, saudação ao sol, banhos coletivos, marchas, campanhas, mídias livres, interações on-line de toda ordem, enfim, a presença de toda a multiplicidade de formas de expressão e de comunicação humana que têm lugar no mundo.

Na medida em que o Fórum foi crescendo colocou-se a questão de que, ocorrendo sempre em Porto Alegre, o FSM impedia a participação de uma imensa gama de movimentos e organizações de outras regiões do mundo que não o conheciam ou não possuíam recursos financeiros suficientes para enviar seus ativistas. O Fórum então passou a ocorrer em diversas regiões, sempre no Sul do mundo. Em 2005, na cidade de Porto Alegre, foi realizada a maior edição de sua história, com mais de 155 mil participantes pertencentes a mais de 6.500 movimentos e organizações de 135 países, distribuídos em cerca de 2.500 atividades autogestionadas ${ }^{16}$. A amplitude e escala do evento revelou inúmeros problemas logísticos e uma enorme dificuldade para criar espaços de tradução nos quais toda essa diversidade pudesse dialogar, se articular e criar agendas comuns. Visando a possibilitar articulações mais fortes e espaços de tradução mais robustos, o FSM descentralizouse e passaram a ocorrer Fóruns locais e regionais em diversas partes do mundo. Essa estratégia era extremamente perigosa porque com ela o Fórum corria o risco de diluir sua força política e 
midiática, que a concentração e a centralização tornavam possível (risco este que, em parte, acabou por se concretizar). Mas, por outro lado, abria a possibilidade de que mais e mais cidades ao redor do mundo realizassem seus próprios Fóruns e, neles, os movimentos de uma mesma região, por estarem mais próximos, cultural e geograficamente, tinham maiores probabilidades de estabelecer zonas de contato, intercâmbios de experiências e articulações de suas lutas e resistências ${ }^{4,9,17}$.

No entanto, apesar de todo o esforço e experimentação empreendidos pelo FSM durante a última década, é preciso reconhecer que os diálogos e as articulações que ele possibilita entre os diferentes movimentos são ainda de baixa intensidade. Isso se deve, entre outros motivos, ao fato de que os movimentos e organizações comparecem ao Fórum em grandes grupos e permanecem fechados em seus grupos ao longo do transcorrer do evento, tendo pouco contato com a diversidade presente.

Não estou com isso a dizer que não há intercambio nem articulações no Fórum. É claro que há. Ao longo de pouco mais de uma década de existência o FSM tornou possível alianças que protagonizaram campanhas globais como a mobilização mundial contra a Guerra ao Iraque, a ampliação e o fortalecimento da Marcha Mundial das Mulheres, que congregou movimentos feministas de todo o mundo, a campanha contra a proposta dos Estados Unidos da Área de Livre Comércio das Américas, a chamada global contra a pobreza, a campanha mundial pela taxação das transações internacionais das grandes empresas, etc. O que estou a dizer é, pura e simplesmente, que esse intercâmbio e articulação possibilitados pelo FSM podem e merecem ser enormemente ampliados para criar agendas comuns mais robustas de luta contra a opressão em suas múltiplas formas.

O esforço do Fórum Social Mundial, em suas sucessivas edições ao redor do mundo, ajudou a criar, nos mais diversos movimentos sociais, uma sensação de incompletude e uma necessidade que não foi ainda plenamente satisfeita, a necessidade de conhecer e de se articular com os demais movimentos que compartilham o inconformismo diante da opressão e a aspiração de um outro mundo possível.

A atual pluralidade de formas de resistência e de concepções de emancipação social exige um espaço no qual essa multiplicidade de formas de ser e estar no mundo possa ser traduzida, pois, para fazer frente à hegemonia global do capitalismo e para construir um sistema econômico e político a favor da vida e do ser humano, não basta que a diversidade de alternativas se manifeste, é preciso que essa diversidade se encontre, dialogue, se articule, se reconheça reciprocamente e se solidarize com os demais. É neste contexto de emergência da diversidade possibilitada pelo FSM e de múltiplos esforços para fazer com que essa infinidade de experiências contra-hegemônicas possam ser reciprocamente inteligíveis que surge a proposta da Universidade Popular dos Movimentos Sociais (UPMS). 


\section{Será possível uma universidade que seja popular e que pertença aos movimentos sociais?}

1. Em janeiro de 2003, Boaventura de Sousa Santos lança, durante a $3^{\text {a }}$ edição do Fórum Social Mundial, a proposta da Universidade Popular dos Movimentos Sociais ${ }^{18}$, "com o objetivo de proporcionar a auto-educação dos ativistas e dirigentes dos movimentos sociais, bem como dos cientistas sociais, dos investigadores e dos artistas empenhados na transformação social progressista"19, e também com o objetivo de "aumentar o conhecimento recíproco entre os movimentos e organizações e tornar possíveis coligações entre eles e ações coletivas conjuntas" 20 .

A proposta foi recebida com entusiasmo e, desde então, ao longo da última década, a UPMS realizou dezenas de oficinas em diversos países da América Latina, África, Europa e Ásia que contaram com a participação de mais de 500 movimentos, organizações, entidades, ativistas, artistas e intelectuais engajados na transformação social. Nessa trajetória a proposta de Santos foi revista e ampliada ${ }^{4,19,21}$, outros autores como Gadotti ${ }^{22}$ e Benzaquen ${ }^{23}$ produziram importantes análises sobre a UPMS. A experiência cresceu, enriqueceu-se enormemente com a contribuição de toda a diversidade de movimentos, organizações, experiências e sujeitos que, desde os mais diversos contextos políticos, geográficos, sociais e culturais, lutam contra a opressão e suas múltiplas faces.

2. Mas é preciso confessar que, à primeira vista, a UPMS causa estranhamento. Inusitada Universidade essa que reivindica ser popular e pertencer aos movimentos sociais: não tem professores nem alunos, não possui nenhum bem material em seu nome, não tem conteúdos programáticos, não oferece aulas, disciplinas ou quaisquer cursos de formação e a condição para participar de suas oficinas é o ativismo social e não o mérito acadêmico. Sentados sempre em grandes círculos, todos são educadores e educandos, todos têm algo de único a dizer e todos são portadores de conhecimentos singulares que fazem falta aos demais.

A diversidade é o rosto dessa estranha Universidade. Nela sentam-se lado a lado indígenas, feministas, lideranças do movimento estudantil, ambientalistas, militantes da luta pela diversidade sexual, trabalhadores da economia solidária, população de rua, sem-terra, sem-teto, quilombolas, ativistas da reforma urbana, sindicalistas, ocuppiers, indignados, pacifistas, migrantes e militantes do movimento negro, todos sem qualquer hierarquia. Toda essa imensa diversidade, a princípio, possui muito pouco em comum. A princípio, há muito mais motivos que os separam do que motivos que os unem, mas nas oficinas da UPMS todos são convidados a ouvir reciprocamente os argumentos uns dos outros, a escutar a legitimidade das aspirações dos demais e a criar plataformas e agendas comuns.

Sendo iguais na diversidade, os movimentos terão de dialogar e desse diálogo fraterno e humano que nada tem a ver com os diálogos imperiais que reproduzem a opressão, desse diálogo de alta intensidade que é também tensão e conflito, surge a possibilidade do Encontro com o Outro, a possibilidade do reconhecimento das divergências e de construção das convergências, a possibilidade de avaliar o que os separa e mesmo assim apostar no que os une, enfim, a possibilidade de uma 
ecologia de saberes capaz de reinventar a emancipação social.

Se o FSM aumenta enormemente o número e diversidade das experiências disponíveis e possíveis, a UPMS visa criar inteligibilidade, coerência e articulação em um mundo enriquecido por uma tal multiplicidade e diversidade de experiências. Tendo nascido no FSM, a UPMS é constituída pelo mesmo espírito e princípios que movem o Fórum e surge como uma experiência que visa expandir e aprofundar os espaços de tradução por ele promovidos, intensificando a construção de um processo de interconhecimento entre movimentos sociais envolvidos com a transformação social para impulsionar ações, campanhas e políticas intermovimentos. "A finalidade é criar, em todos os movimentos ou ONGs, em todas as práticas ou estratégias, em todos os discursos ou saberes, uma zona de contato capaz de os tornar porosos e, portanto, permeáveis a outras ONGs, a outras práticas e estratégias, a outros discursos e saberes"4.

Criar uma "zona de fronteira" capaz de promover o contato, o choque e a interação entre as experiências contra-hegemônicas é, de fato, um desafio imenso que a UPMS busca superar por meio de uma metodologia própria de tradução, de auto-aprendizagem e de inteligibilidade recíproca construída ao longo dos anos em conjunto com toda a diversidade que nela tem lugar. Tal metodologia tangencia os limites da tradução e por isso merece uma análise mais cuidadosa.

\section{A universidade popular dos movimentos sociais e a arquitetura da tradução}

Qual a arquitetura necessária para criar espaços capazes de maximizar as possibilidades de encontro, de tradução e de ecologia de saberes?

É preciso começar por dizer que, assim como o FSM, a UPMS faz um uso pragmático da tradução orientando-a para um fim político, ou seja, concebe a tradução enquanto ferramenta a serviço das experiências contra-hegemônicas, ferramenta essa que pode e deve ser utilizada para construir novas e plurais concepções de emancipação social. A UPMS esforça-se para criar novos espaços e metodologias de tradução porque entende que "só através da inteligibilidade recíproca e consequente possibilidade de agregação entre saberes não-hegemônicos é possível construir a contra-hegemonia"14.

No entanto, diferentemente do Fórum Social Mundial, a Universidade Popular dos Movimentos Sociais não é um espaço aberto (muito embora se reivindique como tal), em outras palavras, não é qualquer pessoa ou movimento que pode, por espontânea vontade, participar das oficinas realizadas pela UPMS. Este é um fator fundamental que simultaneamente limita e potencializa a UPMS e que é decisivo para compreender as diferenças entre as duas experiências de tradução. Se é verdade que o espaço aberto do FSM torna possível a emergência de uma diversidade infinita de experiências, não é menos verdade que este mesmo espaço aberto torna muito difícil a tradução tal como foi exposto no capítulo acima.

A UPMS, buscando viabilizar os processos de tradução entre os movimentos, opta por convidar ISSN 1982-8829 Tempus, actas de saúde colet, Brasília, 8(2), 257-273, jun, 2014// 
$266 / /$

os participantes de suas oficinas baseando-se em critérios de diversidade temática, diversidade organizativa, diversidade de escalas e de atuação, diversidade de práticas e de concepções políticas, raça, classe, idade, sexo, localização geográfica, etc. Critérios que têm como objetivo fazer com que um pequeno grupo de 30 a 50 participantes, convidados para oficinas com duração de 2 a 3 dias, seja portador da maior diversidade possível. Esse pequeno grupo fechado, escolhido autonomamente pelos movimentos organizadores de cada uma das oficinas, tendo como referência os critérios da carta de metodologia da $\mathrm{UPMS}^{20}$, tem a fraqueza de não abarcar toda a multiplicidade de experiências existentes, mas tem a vantagem de criar as condições necessárias para um diálogo e um interconhecimento minimamente coerente entre a diversidade presente. Isso porque:

a) A oficina é realizada a partir de uma relação horizontal entre todos os seus integrantes, de maneira que não há um sujeito ou movimento privilegiado sobre os demais.

b) O método de convocação, em geral, convida um único ativista de um mesmo movimento, o que impede que eles se fechem em seus próprios grupos como, por vezes, acontece no Fórum.

c) Os participantes (inclusive os intelectuais) são todos hospedados em um mesmo local, promovendo entre eles encontros informais de convívio para além dos espaços tradicionais de debate e reflexão.

d) Os momentos de lazer, as místicas e as refeições da oficina são sempre realizadas de maneira coletiva, sendo todos os participantes "companheiros" no sentido literal da palavra, que em sua raiz significa "aqueles que compartem o pão".

e) Além de dormir, comer e vivenciar atividades culturais com pessoas até então desconhecidas provenientes das mais diversas partes do mundo e imbricadas nas mais variadas formas de combate e de resistência a opressão, durante os momentos de oficina estes participantes são convidados a partilhar suas lutas, posições, ideais, discursos, objetivos, organização, práticas de intervenção e estratégias de ação.

Além de todas estas estratégias, é adotado também o princípio de que as oficinas devem ser constituídas por apenas um terço de "intelectuais militantes", e por dois terços de ativistas e lideranças de organizações ou movimentos sociais ${ }^{20}$. Esse critério cria as condições para a construção de um processo pedagógico baseado em uma ecologia de saberes que combina os conhecimentos nascidos nas lutas com os conhecimentos que, tendo sua origem na universidade, solidarizam-se com as lutas.

Por um lado, os intelectuais militantes contribuem para que os movimentos possam aprofundar a compreensão crítica e reflexiva sobre suas próprias práticas. Por outro lado, os movimentos contribuem para a aprendizagem dos intelectuais militantes ao apresentarem suas formas de conceber 
o mundo e suas estratégias para transformá-lo.

A metodologia da UPMS inspira-se em Paulo Freire e na longa tradição de educação popular que existe na América Latina, mas inova ao dissolver por completo a distinção entre educador e educandos, dando um passo adiante na proposta de Freire. Claro está que Freire reconhece os educandos como sujeitos de saber, não por acaso, um dos capítulos de sua Pedagogia do Oprimido chama-se "Ninguém liberta ninguém, ninguém se liberta sozinho, os homens se libertam em comunhão"24. No entanto, é inegável que no método proposto por Freire há um educador que se diferencia dos educandos, um educador que troca, que dialoga, que aprende com os educandos, mas que é, em última instância, o educador. Na UPMS não há essa distinção, pois parte-se de um princípio de horizontalidade, de modo que não há sequer a figura de alguém que coordene o espaço e as atividades, há tão somente facilitadores que são definidos entre os próprios participantes no início da oficina.

Há, obviamente, que se levar em conta o fato de que os contextos de Freire e da UPMS são distintos e que é o próprio Freire quem, muito sabiamente, já dizia: “a única maneira que alguém tem de aplicar, no seu contexto, alguma das proposições que fiz é exatamente refazer-me, quer dizer, não seguir-me. Para seguir-me, o fundamental é não me seguir" ${ }^{25}$. No contexto de Freire, a figura do educador é, de fato, imprescindível, porque há uma condição de assimetria, há pessoas que estão sendo alfabetizadas e, portanto, é necessário que exista um educador. O contexto em que a UPMS ocorre é diferente, não é um contexto de ensino ou de alfabetização, é um contexto em que todos já partem de uma condição de horizontalidade, pois possuem uma robusta experiência de resistência e de lutas sociais. É esse contexto de horizontalidade que torna possível a supressão da figura do educador, reinventando a proposta de Freire sem se contrapor a ela. Na UPMS todos os participantes são igualmente reconhecidos como portadores de saberes e práticas que interessam aos demais, ou seja, há o reconhecimento de que o Outro diante de nós tem algo que nos falta. Se somos todos incompletos e se temos todos o que aprender com os demais, não faz qualquer sentido a ideia de que uns estejam a educar e outros a aprender.

Como é possível imaginar, as relações entre os movimentos e a universidade possibilitados pelas oficinas são um aprendizado muito exigente para os intelectuais que, acostumados a falar e a ensinar, terão também de ouvir e aprender; acostumados a impor a importância de suas teorias, terão que negociá-las com os demais saberes presentes. E são também muito exigentes para a própria UPMS, pois a forma como se equaciona as relações de poder entre o conhecimento científico e os demais saberes que compartilham com ele a existência no mundo reduz ou amplia a qualidade das traduções possíveis.

Quanto maior a qualidade das traduções, menores serão os preconceitos mútuos entre os movimentos e, portanto, maiores e mais diversificadas serão as zonas de contato entre eles. É, por exemplo, muito comum, durante o trabalho de tradução nas oficinas, os movimentos perceberem a proximidade de práticas que, entretanto, nomeiam de diferentes maneiras em suas lutas concretas. 
De fato, o que ocorre muitas vezes é que diferentes movimentos utilizam terminologias distintas para nomear práticas bastante semelhantes. As experiências de ocupação de terras são emblemáticas nesse sentido.

Por um lado, há movimentos que pretendem fazer da permanência na terra um fato político de luta por direitos e, por isso, nomeiam suas ações de "ocupação". Por outro lado, os movimentos que optam pela institucionalização de suas demandas chamam de "invasão", pois os que invadiram estão "furando a fila" das famílias que esperam pelas políticas públicas. Também há os movimentos mais radicais que reivindicam a expressão "invasão" para indicar que estão enfrentando a propriedade agrária, o latifúndio e o capital. Como se não bastasse, há ainda os movimentos que adotam como estratégia de permanência na terra ocupada a utilização do nome "comunidade", entendendo que esta expressão tem menos carga simbólica que "ocupação" ou "invasão" e pode, portanto, atrair a simpatia de um grupo mais alargado de apoiadores. O termo "comunidade" é também reivindicado pelos movimentos que pretendem com sua utilização passar a mensagem de direito consolidado pelo tempo de uso, como é o caso das comunidades tradicionais quilombolas. E, por fim, mas não menos importante, há ainda movimentos indígenas que optam por dar o nome de "retomada" às suas ações de ocupação para significar o fato de que reivindicam uma terra que antes pertencia a eles e que lhes foi roubada.

A ação (ocupar terras para exigir direitos) é a mesma em todos os casos, mas os objetivos, justificações e intencionalidades que cada movimento dá a essa mesma ação são tão múltiplos e diversos quanto as formas de opressão que recaem sobre eles e com as quais se enfrentam.

Mas não haverá nada em comum entre as "ocupações" camponesas, as "comunidades" quilombolas e as "retomadas" indígenas? Não terão eles nada que aprender uns com os outros? Não seriam possíveis ações conjuntas entre estes movimentos? É claro que sim, e é justamente isso que o trabalho de tradução promovido pela UPMS visa identificar, pois, mesmo entre os movimentos mais diversos, há sempre a viabilidade de insuspeitadas formas de interação e articulação.

Não é raro, portanto, que ao longo do trabalho de tradução um dado movimento se aproprie de determinadas práticas ou terminologias de outros movimentos em um contexto totalmente diverso, tendo em sua utilização outros objetivos e produções de sentido, diferentes do inicial. O trabalho da tradução permite o desmembramento de signos e práticas, tornando possível a sua re-significação contendo outras intencionalidades. Nesse sentido o movimento da Reforma Urbana, por exemplo, pode adotar técnicas de ocupação semelhantes às do MST, não propriamente para reivindicar o direito à terra, e sim para reivindicar o direito a espaços culturais. Mas porque não a Reforma Urbana tematizar o direito à terra nas cidades e o MST tematizar o direito a espaços culturais nos assentamentos rurais? Um trabalho de tradução bem sucedido entre os dois movimentos certamente os levará a incorporar certas práticas e ideias uns dos outros, resignificando-as para que façam sentido e possam ser úteis em seus próprios contextos. 
Obviamente que essa inteligibilidade recíproca tem seus limites, afinal, como nos recorda Said apud Rodriguez, a tradução é "um processo pelo qual todos nós nos enfrentamos com nossa própria falta de habilidade para compreender a experiência dos outros, inclusive quando reconhecemos a absoluta necessidade de seguir empenhados nessa tarefa"26.

Podemos traduzir os conceitos de "Sumak Kawsay" ou de "Pachamama" para a nossa realidade, mas isso não nos torna capazes de compreender o significado profundo que eles possuem na cosmovisão andina. Por maior que seja a nossa abertura e a intensidade dos diálogos estabelecidos, não há nem haverá nunca tradução para o genocídio cometido contra os povos indígenas ou para a escravidão imposta durante séculos aos negros. A UPMS reconhece esses limites da tradução e é justamente sobre eles que se tenta atuar durante as oficinas, não necessariamente para superá-los, mas para ao menos conhecê-los. Foi o que ocorreu, por exemplo, na oficina "Saúde, sustentabilidade e buen vivir" realizada no município de Aldeia Velha, em 2012, onde a diversidade de movimentos presente foi provocada a pensar a saúde em termos de bem viver.

A tradução é sempre uma luta contra o intraduzível assim como o diálogo, quando verdadeiro, é sempre conflitual. Quando entramos em um processo de tradução somos obrigados a pôr em causa nossos próprios quadros de referência, nossa linguagem, nossas práticas e, no limite, nossas formas de conceber o mundo. Obviamente, um processo exigente como este não poderia ocorrer sem ser permeado por conflitos, tensões e fortes contradições, não sendo de esperar outra coisa das relações estabelecidas entre os movimentos na UPMS.

Em geral, a metodologia de tradução proposta pela UPMS é capaz de gerir tais tensões e conflitos, direcionando a ênfase do debate para o que nos une, sem nunca ignorar o que nos separa. No entanto, há casos em que as diferenças de posições acerca de determinados temas são tão conflituais que tornam muito difícil a tradução. Foi o que ocorreu, por exemplo, na oficina de Tunis em 2013, quando duas posições a respeito do feminismo foram incapazes de estabelecer um diálogo que resultasse em inteligibilidade recíproca. De um lado havia os movimentos que faziam furiosas críticas ao modo como o islão concebe as mulheres na sociedade; do outro lado, movimentos que defendiam o uso da burca ou o respeito à sharia (código de leis do islamismo em que não há separação entre a religião e o direito) como reivindicações emancipatórias e que propunham um feminismo árabe partindo de pressupostos não-ocidentais.

Os limites da tradução tornam-se ainda mais evidentes quando se tenta passar da inteligibilidade recíproca para a articulação de ações comuns entre os movimentos. Para além do que podemos aprender uns com os outros é preciso avançar para o que podemos realizar em conjunto e este é, sem dúvida, o momento mais difícil da tradução, porque as ações conjuntas implicam o investimento de tempo e de recursos dos diferentes movimentos, o que exige um alto nível de confiança recíproca entre eles para que assumam os riscos inerentes às ações deste tipo.

Consciente destas dificuldades, a UPMS se esforça para, no final de suas oficinas, criar um 
espaço onde "os participantes, em diálogo aberto, imaginam e propõem ações, intervenções, lutas e campanhas que poderiam ser levadas a cabo conjuntamente com todos os movimentos/organizações ou com alguns deles" ${ }^{20}$. Deste espaço criado ao fim da oficina pode ou não surgir um relativo consenso sobre o engajamento de todos em alguma das propostas de ações conjuntas. Em 2012, por exemplo, houve uma grande e violenta remoção forçada no estado de São Paulo durante os dias em que ocorria a oficina de Porto Alegre. Os movimentos participantes, oriundos das mais diversas lutas e nacionalidades, decidiram então que fariam em conjunto um vídeo de repudio à remoção forçada denunciando a violência policial e a criminalização dos protestos sociais.

Embora seja possível dar outros exemplos semelhantes tanto de tensões como de articulações entre os movimentos possibilitadas pela metodologia de tradução desenvolvida nas oficinas da UPMS, o fato é que "o que continua difícil de conseguir é uma coalizão forte entre comunidades minoritárias e formações políticas baseada no reconhecimento de um conjunto de objetivos comuns"27.

\section{CONSIDERAÇÕES FINAIS}

O objetivo deste trabalho foi estabelecer comparações possíveis entre duas experiências de tradução e de ecologia de saberes que comungam a utopia de um outro mundo possível. Duas experiências quixotescas, no sentido de que se encontram, tal como o célebre personagem de Cervantes $^{28}$, entre a aspiração aos valores ideais e a impossibilidade de realizá-los plenamente.

Longe de se reduzir à linguagem ou mesmo ao intercambio cultural, no FSM e na UPMS a tradução assume o caráter de um instrumento político a serviço das lutas contra-hegemônicas. Nas duas experiências o trabalho da tradução tem o objetivo político de viabilizar a ecologia de saberes, tornando possível a articulação dos movimentos sociais de forma a constituírem objetivos comuns de resistência e de luta contra as múltiplas formas de opressão perpetuadas pelo capitalismo, pelo colonialismo e pelo patriarcado.

O FSM foi capaz de trazer a tona as mais diversas e impronunciáveis aspirações de justiça e dignidade, tornando visíveis e credíveis as alternativas emergentes. Foi também capaz de congregálas em um mesmo espaço, mas tem sido pouco eficaz em promover processos de tradução e diálogos de alta intensidade entre essas mesmas alternativas. A UPMS não tem a amplitude, nem a escala, nem o poder de alcance, atração e agregação do FSM, mas avança ao propor um método de tradução que possibilita a inteligibilidade recíproca e maximiza as chances de articulação entre os movimentos que nela participam. Embora tenham tornado possíveis constelações de lutas que há poucos anos seriam impensáveis, o limite das duas experiências é não terem sido suficientemente capazes de transformar a riqueza da diversidade e os resultados da tradução em ações efetivamente transformadoras.

Por fim, vale recordar que este artigo começou com uma pergunta forte: "Quais os saberes que nos faltam para captar e articular a diversidade do mundo?" Agora, em sua conclusão, após a análise 
comparativa entre o Fórum e a UPMS, podemos alargar e complexificar a pergunta forte que deu origem a toda essa reflexão perguntando: "Quais as sensibilidades que nos faltam para captar e articular a diversidade infinita do mundo?" Porque, se é certo que nos faltam conhecimentos, é igualmente certo que o conhecimento não basta para captar a diversidade e muito menos para articulá-la.

É preciso debater quais as estratégias políticas necessárias para construir um outro mundo possível, sem dúvida que sim, mas é preciso também debater quais paixões e utopias são necessárias para construir um outro mundo possível. Quais os sonhos, poesias, valores, éticas, cores, cheiros e sabores darão consistência a este outro mundo? De quantas lutas, afetos e ternuras será feito um outro mundo possível? De quantas esperanças e desejos, beijos e abraços, gentilezas e entregas, carinhos, encontros e solidariedades será feito um outro mundo possível? Em outras palavras, qual o Amor que nos falta para articular a diversidade rumo à construção dos outros mundos que desejamos?

O que está em jogo nos processos levados a cabo pelo FSM e pela UPMS é como contribuir para a criação de laços fortes de solidariedade e para o encontro fraterno e humano das comunidades, dos movimentos, dos oprimidos do mundo. O que está em jogo é a construção coletiva de processos de tradução capazes de ir mais além do desejo de reconhecermos a nós mesmos no Outro, porque, ao fim e ao cabo, ninguém luta para ouvir o próprio eco, nem para ver a própria imagem em um espelho.

\section{REFERÊNCIAS}

1. Asad T. The Concept of Cultural Translation in British Social Antropology. In: Clifford J, Marcus G. The poetics and politics of etnography. Los Angeles: University of California Press. 1986.

2. Graça RSFS. Tradução cultural e política: recepção de Walter Benjamin em Homi Bhabha. Anais do VII Seminário de Pós-Graduação em Filosofia da UFSCar. São Carlos: UFSCar. 2011.

3. Ribeiro AS. A Tradução como Metáfora da Contemporaneidade. Eurozine. 2005. Disponível em: http://www.eurozine.com/pdf/2005-07-18-ribeiro-pt.pdf.

4. Santos BS. Fórum Social Mundial: Manual de uso. São Paulo: Cortez. 2005.

5. Santos BS. Para além do Pensamento Abissal: Das linhas globais a uma ecologia de saberes. Revista Crítica de Ciências Sociais. 2007; 78:3-46.

6. Fukuyama F. The end of history. The national interest. 1989.

7. Ramonet I. O novo século começa em Porto Alegre. Le Monde Diplomatique. 2001. 
8. Santos BS. El Foro Social Mundial y la Izquierda Global. El Viejo Topo. 2008; 240:39-62.

9. Whitaker F. O Desafio do Fórum Social Mundial: Um modo de ver. São Paulo: Loyola. 2005.

10. Gadotti M. Educar para um outro mundo possível. São Paulo: Publisher Brasil. 2007.

11. Leite JC. Fórum Social Mundial: A história de uma invenção política. São Paulo: Fundação Perseu Abramo. 2003.

12. Santos BS. Poderá o Direito ser emancipatório?. Revista Crítica de Ciências Sociais. 2003; 65:3-76.

13. Santos BS. A Crítica da Razão Indolente: Contra o Desperdício da Experiência. $7^{\mathrm{a}}$ Ed. São Paulo: Cortez. 2000.

14. Santos BS. Para uma sociologia das ausências e uma sociologia das emergências. Revista Crítica de Ciências Sociais. 2002; 63:237-280.

15. Santos BS. A filosofia à venda, a douta ignorância e a aposta de Pascal. Revista Crítica de Ciências Sociais. 2008; 80:11-43.

16. Instituto Brasileiro de Análises Sociais e Econômicas (IBASE). Raio X da participação no Fórum 2005: Elementos para o debate. Rio de Janeiro: IBASE. 2005.

Disponível em: http://www.ibase.br/pt/wp-content/uploads/2011/06/fsm-raio-X-daparticipa $\% \mathrm{C} 3 \% \mathrm{~A} 7 \% \mathrm{C} 3 \% \mathrm{~A} 30-2005 . \mathrm{pdf}$.

17. Rabelo AMP. Três estrelas do Sul Global: O Fórum Social Mundial em Mumbai, Nairóbi e Belém. (Tese de doutorado). Belo Horizonte: UFMG. 2011.

18. Santos BS. Proposta de auto-aprendizagem coletiva e transformadora: a Universidade Popular dos Movimentos Sociais. Terraviva. Porto Alegre. 2003; 78-83.

19. Santos BS. A Gramática do Tempo: Para uma nova cultura política. $3^{\text {a }}$ Ed. São Paulo: Cortez. 2010 .

20. Universidade Popular dos Movimentos Sociais (UPMS). Orientações metodológicas das oficinas da Universidade Popular dos Movimentos Sociais. 2012. Disponível em: http://www. universidadepopular.org/site/media/documentos/Orientacoes_metodologicas_UPMS - portugues. pdf.

21. Benzaquen JF. A Universidade Popular dos Movimentos Sociais: entrevista com o prof. Boaventura de Sousa Santos. Educação e Sociedade. 2012; v. 33; n. 120:917-927. 
22. Gadotti M. Universidade Popular dos Movimentos Socais: breve história de um sonho possível. 2009.

Disponível em: http://www.universidadepopular.org/media/relatos\%20oficinas/Gadotti.pdf.

23. Benzaquen JF. Universidades dos Movimentos Sociais: apostas em saberes, práticas e sujeitos descoloniais. (Tese de doutorado). Coimbra: UC. 2012.

24. Freire P. Pedagogia do Oprimido. 50 a Ed. Rio de Janeiro: Paz e Terra. 2011.

25. Freire P, Faundez A. Por uma pedagogia da pergunta. São Paulo: Paz e Terra. 1985.

26. Rodriguez EG. Translating Positionality: On Post-Colonial Conjunctures and Transversal Understanding. Transversal. 2006.

Disponível em: http://translate.eipcp.net/transversal/0606/gutierrez-rodriguez/en.

27. Butler J. Competing Universalities. In: Butler J, Laclau E, Zizek S. Contingency, Hegemony, Universality: Contemporary dialogues on the left. New York: Verso. 2000.

28. Cervantes M. Don Quijote de la Mancha. Madrid: Juan de la Cuesta. 1605. 